\title{
Thermoelastic Analysis of Disk Brakes Rotor
}

\author{
Bouchetara Mostefa, Belhocine Ali \\ Department of Mechanical Engineering, USTO University, Oran, Algeria \\ *Corresponding author: al.belhocine@yahoo.fr
}

Received May 29, 2014; Revised June 16, 2014; Accepted August 20, 2014

\begin{abstract}
The main purpose of this study is to analyze the thermomechanical behavior of the dry contact between the brake disk and pads during the braking phase. The simulation strategy is based on computer code ANSYS11. The modeling of transient temperature in the disk is actually used to identify the factor of geometric design of the disk to install the ventilation system in vehicles The thermal-structural analysis is then used with coupling to determine the deformation and the Von Mises stress established in the disk, the contact pressure distribution in pads. The results are satisfactory when compared to those of the specialized literature.
\end{abstract}

Keywords: brake disks, heat flux, heat transfer coefficient, von mises stress, contact pressure

Cite This Article: Bouchetara Mostefa, and Belhocine Ali, "Thermoelastic Analysis of Disk Brakes Rotor." American Journal of Mechanical Engineering, vol. 2, no. 4 (2014): 103-113. doi: 10.12691/ajme-2-4-2.

\section{Introduction}

The braking process is in fact the matter of energy balance. The aim of braking system is to transform mechanical energy of moving vehicle into some other form, which results in decreasing the speed of the vehicle. The kinetic energy is transformed into the thermal energy, by means of dry friction effects, which then is, dissipated into the surroundings [1].

The friction heat generated between two sliding bodies causes thermoelastic deformation which alters the contact pressure distribution. This coupled thermo-mechanical process is referred to as frictionally-excited thermoelastic instability or TEI [2]. If the sliding speed is above one called critical speed, the resulting thermo-mechanical feedback is unstable, leading to the development of nonuniform contact pressure and local high temperature with important gradients called 'hot spots' [3]. The formation of such localized hot spots is accompanied by high local stresses that can lead to material degradation and eventual failure [4]. Also, the hot spots can be a source of undesirable frictional vibrations, known in the automotive disk brake community as 'hot roughness' or 'hot judder' [5].

In 2002, Nakatsuji et al. [6] conducted a study on the initiation of hair-like cracks which are formed around small holes in the flanges of one-piece disks during overloading conditions. The study showed that thermally induced cyclic stress strongly affects the crack initiation in the brake disks. In order to show the crack initiation mechanism, the temperature distribution at the flange was firstly measured. The temperature distribution under overloading was analyzed by using the finite element method. Based on the experimental and calculated results, the crack initiation mechanism for one-piece brake disks at the very severe braking condition was explained. In addition, the effective methods are suggested for reducing the initiation of tiny cracks around the holes.
In 2000, Valvano and Lee [7] conducted a study of the technique to determine the thermal distortion of a brake rotor. The severe thermal distortion of a brake rotor can affect important brake system characteristics such as the system response and brake judder propensity. As such, the accurate prediction of thermal distortions can help in the designing of a brake disk.

In 1997, Hudson and Ruhl [8] conducted a study of the air flow through the passage of a Chrysler LH platformventilated brake rotor. Modifications to the production rotor's vent inlet geometry were prototyped and measured, in addition to the production rotor. Vent passage air flow was compared with the existing correlations. With the aid of Chrysler Corporation, investigation of ventilated brake rotor vane air flow was undertaken. The goal was to measure current vane air flow and to improve this vane flow to increase brake disk cooling. Temperature increases can strongly influence the properties of the surface of materials in slip, support physicochemical and microstructural transformations, and modify the rheology of interfacial elements trapped in the contact zone [9]. Recent numerical models, presented to deal with rolling processes $[10,11]$ have shown that the thermal gradients can attain important levels which depend on the heat dissipated by friction, the rolling speed, and the heat transfer coefficient. Many other studies [12,13] dealt with the evaluation of temperature in solids subjected to frictional heating. The temperature distribution due to friction process necessitates a good knowledge of the contact parameters. In fact, the interface is always imperfect-due to the roughness - from mechanical and thermal points of view. Recently, theoretical and experimental studies [14,15] have been developed to characterize the thermal parameters which govern the heat transfer at the vicinity of a sliding interface. In certain industrial applications, the solids are provided with a surface coating. A recent study has been carried out to analyze the effect of surface coating on the thermal 
behavior of a solid subjected to the friction process [16]. Increased thermal efficiency and the integrity of materials in high-temperature environments is an essential requirement in modem engineering structures in automotive, aerospace, nuclear, offshore, environmental, and other industries. Nowadays, the FE method is used regularly to obtain numerical solutions for heat transfer problems. The most common choice when using finite elements is the standard Galerkin formulation [17].

Gao and Lin [18] have presented an analytical model for the determination of the contact temperature distribution on the working surface of a brake. To consider the effects of the moving heat source (the pad) with relative sliding speed variation, a transient finite element technique is used to characterize the temperature fields of the solid rotor with appropriate thermal boundary conditions. Numerical results shows that the operating characteristics of the brake exert an essentially influence on the surface temperature distribution and the maximal contact temperature.

Talati and Jalalifar [19] presented a paper on Analysis of heat conduction in a disk brake system. In this paper, the governing heat equations for the disk and the pad are extracted in the form of transient heat equations with heat generation that is dependant to time and space. In the derivation of the heat equations, parameters such as the duration of braking, vehicle velocity, geometries and the dimensions of the brake components, materials of the disk brake rotor and the pad and contact pressure distribution have been taken into account. The problem is solved analytically using Green's function approach. It is concluded that the heat generated due to friction between the disk and the pad should be ideally dissipated to the environment to avoid decreasing the friction coefficient between the disk and the pad and to avoid the temperature rise of various brake components and break fluid vaporization due to excessive heating.

Naji et al. [20] presented a mathematical model to describe the thermal behavior of a brake system which consists of the shoe and the drum. The model is solved analytically using Green's function method for any type of the stopping braking action. The thermal behavior is investigated for three specified braking actions which were the impulse, the unit step and trigonometric stopping actions.

Thermal response of disk brake systems to different materials used for the disk-pad couple has been studied in many researches [21-28]. Aerodynamic cooling of high performance disk brake systems is investigated by many researchers [29,30,31].

Kang and Cho [32] was conducted to analyze the geometry of vents in motorcycle disk brakes which affects the surface of the disk. To analyze the thermal characteristics of disk brakes, thermal deformation analysis and thermal stress analysis due to heat transfer was carried out through the finite element analysis for ventilated disk and solid disk. For 3-dimensional modeling and finite element analysis of the disks, the commercial code ANSYS Workbench was used.

Thilak VMM et al. [33] conducted a transient thermal and structural analysis of a brake disk to evaluate its performance under severe braking conditions and there by assist in disk rotor design and analysis. The usage of new materials was investigated which aims at improving the braking efficiency and providing greater stability to the vehicle. This study was done using ANSYS 11 software to analyze the temperature distribution, variation of the stresses and deformation across the disk brake profile. The new materials under study were Aluminum base metal matrix composite and High Strength Glass Fiber composites. These materials have a promising friction and wear behavior as a brake disk. The transient thermo elastic analysis of disks in repeated brake applications was performed and the results were compared to that of cast iron disk. In the study conducted by Zhang et al. [34] A non-linear FEM model of brake discs of high-speed trains with thermal-mechanical coupling has been established in ANSYS. The simulation and analysis of 3-D transient temperature field and stress field of brake discs have been carried out for the braking process. According to typical imperfections of brake discs, some imperfection models of brake discs have been developed and the thermal stresses of different models are obtained through simulation and analysis.

In this study, we will make a modeling of the thermomechanical behavior of the dry contact between the disks of brake pads at the time of braking phase; the strategy of calculation is based on the software ANSYS 11. This last is comprehensive mainly for the resolution of the complex physical problems. The numerical simulation of the coupled transient thermal field and stress field is carried out by sequentially thermal-structurally coupled method based on ANSYS.

\section{Heat Flux Entering the Disk}

In the case of disk brake, the effective friction processes between the pads and the disk are extremely complex because the present time brake pads, due to their composite structure [35], do not have constant chemicalphysical properties, with the organic containing elements being subjected to a series of transformations under the influence of temperature increase. The heat distribution between the brake disk and the friction pads is mostly dependent on material characteristics, a major influence among which arises from the densities $\rho_{d, g}\left[\mathrm{~kg} / \mathrm{m}^{3}\right]$, the thermal conductivities $k_{d, g}\left[\mathrm{~W} / \mathrm{m}{ }^{\circ} \mathrm{C}\right]$ and the specific heats $c_{d, g}\left[\mathrm{~J} / \mathrm{kg}{ }^{\circ} \mathrm{C}\right]$ of the disk's (subscript $d$ ), and the braking pad's materials, respectively (subscript $g$ ). Denoting $Q_{d}$ and $Q_{g}[\mathrm{~J}]$, as the heat quantities assumed by the disk and the braking pads, respectively, one can express in the following manner [36]:

$$
\frac{Q_{d}}{Q_{g}}=\frac{\sqrt{\rho_{d} \bullet k_{d} \cdot C_{d}}}{\sqrt{\rho_{g} \cdot k_{g} \cdot C_{g}}}
$$

Because the braking disk is not entirely covered by the friction pads, while computing, we have to consider the ratio between the disk surface $S_{d}$ and the pad surface $S_{g}$. Denoting the ratio of heat's division between the disk and pads as:

$$
\varphi_{c}=\frac{Q_{d}}{Q_{g}} \cdot \frac{S_{d}}{S_{g}}=\frac{\sqrt{\rho_{d} \cdot k_{d} \cdot C_{d}}}{\sqrt{\rho_{g} \cdot k_{g} \cdot C_{g}}} \cdot \frac{S_{d}}{S_{g}}
$$


and considering $Q[\mathrm{~J}]$ the heat quantity generated during the friction process, the heat quantities assumed by the pads and the disk are, respectively,

$$
\begin{aligned}
Q_{g} & =Q \cdot \frac{1}{1+\varphi_{c}} \\
Q_{d} & =Q \cdot \frac{\varphi_{c}}{1+\varphi_{c}}
\end{aligned}
$$

Figure 1 shows the ventilated disk - pads and the applied forces.

The geometrical characteristics of the ventilated disk are illustrated in Figure 2.

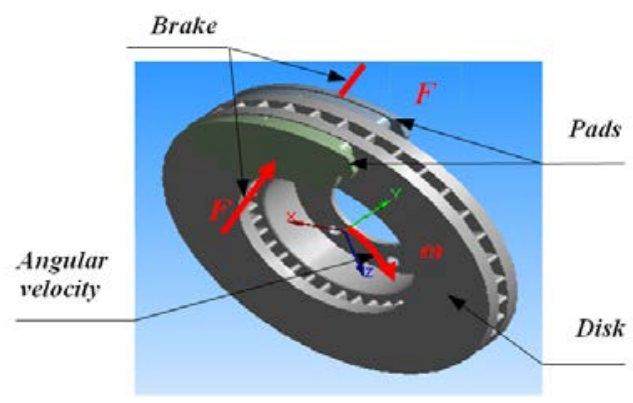

Figure 1. Disk-pads assembly with forces applied to the disk

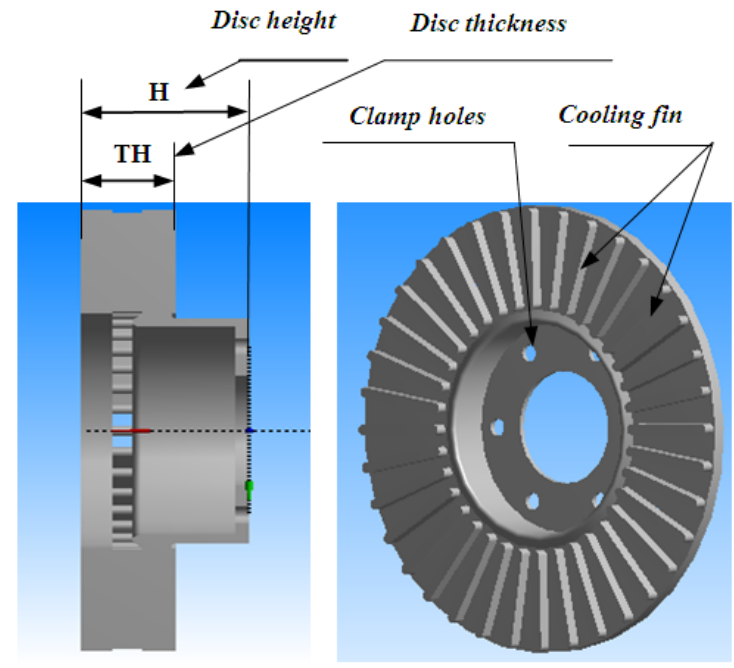

Figure 2. Geometrical characteristics of the ventilated disk

The brake disk consumes the major part of the heat, usually grater than $90 \%$ [37], by means of the effective contact surface of the friction coupling. Considering the complexity of the problem and the limitation in the average data processing, one identifies the pads by their effect, represented by an entering heat flux (Figure 3).

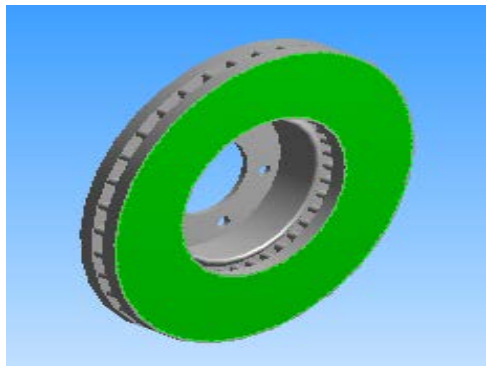

Figure 3. Application of flux
The initial heat flux $q_{0}$ entering the disk is calculated by the following formula [38]:

$$
q_{0}=\frac{1-\phi}{2} \cdot \frac{m g v_{0} z}{2 A_{d} \varepsilon_{p}}
$$

Where $z=a / g$ is the braking effectiveness, $a$ is the deceleration of the vehicle $\left[\mathrm{m} / \mathrm{s}^{2}\right], \phi$ is the rate distribution of the braking forces between the front and rear axle, $A_{d}$ disk surface swept by a brake pad $\left[\mathrm{m}^{2}\right] . v_{0}$ is the Initial speed of the vehicle $[\mathrm{m} / \mathrm{s}], \varepsilon_{p}$ is the factor load distribution on the surface of the disk., $m$ eht si mass of the vehicle [kg] and $g$ is the acceleration of gravity (9.81) $\left[\mathrm{m} / \mathrm{s}^{2}\right]$.

The loading corresponds to the heat flux on the disk surface. The dimensions and the parameters used in the thermal calculation are recapitulated in Table 1.

Table 1. Parameters of automotive brake application

\begin{tabular}{|c|c|}
\hline Inner disk diameter, mm & 66 \\
\hline Outer disk diameter, mm & 262 \\
\hline Disk thickness (TH), mm & 29 \\
\hline Disk height (H), mm & 51 \\
\hline Vehicle mass $m, \mathrm{~kg}$ & 1385 \\
\hline Initial speed $v_{0}, \mathrm{~km} / \mathrm{h}$ & 28 \\
\hline Deceleration $a, \mathrm{~m} / \mathrm{s}^{2}$ & 8 \\
\hline Effective rotor radius $R_{\text {rotor }}, \mathrm{mm}$ & 100.5 \\
\hline Rate distribution of the braking forces $\phi, \%$ & 20 \\
\hline Factor of charge distribution of the disk $\varepsilon_{p}$ & 0.5 \\
\hline Surface disk swept by the pad $A_{d}, \mathrm{~mm}^{2}$ & 35993 \\
\hline
\end{tabular}

Table 2. Thermoelastic properties used in simulation

\begin{tabular}{|c|c|c|}
\hline Material Properties & Pad & Disk \\
\hline Thermal conductivity, $k\left(\mathrm{~W} / \mathrm{m}^{\circ} \mathrm{C}\right)$ & 5 & 57 \\
\hline Density, $\rho\left(\mathrm{kg} / \mathrm{m}^{3}\right)$ & 1400 & 7250 \\
\hline Specific heat, $C\left(\mathrm{~J} / \mathrm{Kg}^{\circ} \mathrm{C}\right)$ & 1000 & 460 \\
\hline Poisson's ratio, $v$ & 0.25 & 0.28 \\
\hline Thermal expansion, $\alpha\left(10^{-6} /{ }^{\circ} \mathrm{C}\right)$ & 10 & 10.85 \\
\hline Elastic modulus, $E(\mathrm{GPa})$ & 1 & 138 \\
\hline Coefficient of friction, $\mu$ & 0.2 & 0.2 \\
\hline Operation Conditions & & \\
\hline Angular velocity, $\omega(\mathrm{rd} / \mathrm{s})$ & & 157.89 \\
\hline Hydraulic pressure, $P(\mathrm{MPa})$ & & 1 \\
\hline
\end{tabular}

The disk material is gray cast iron (GF) with high carbon content [39], with good thermophysical characteristics, and the brake pad has an isotropic elastic behavior, thermomechanical characteristics of which adopted in this simulation of the two parts are recapitulated in Table 2 .

The thermal conductivity and specific heat are a function of temperature, Figure 4 and Figure 5. 


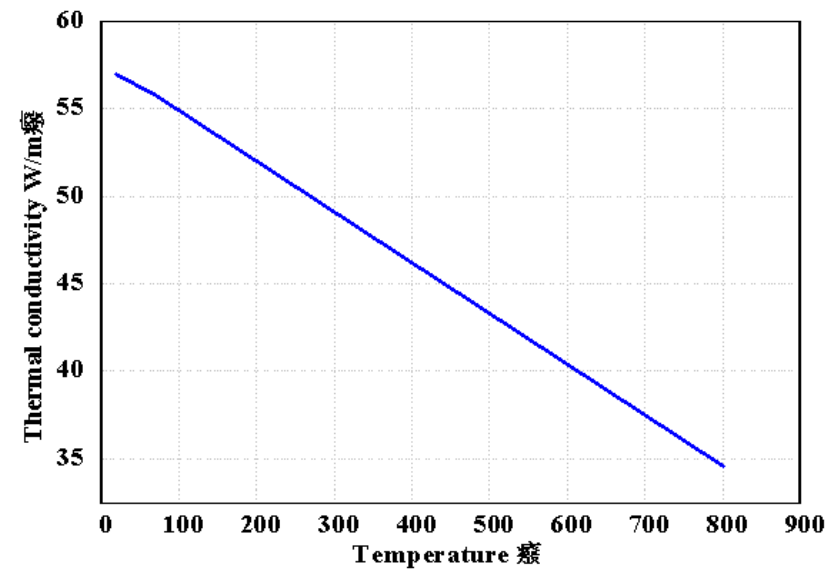

Figure 4. Thermal conductivity versus temperature

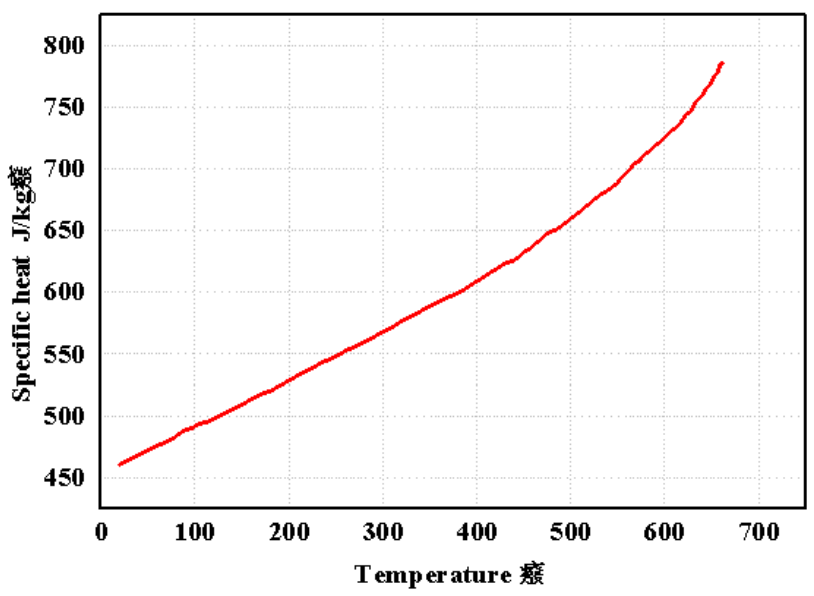

Figure 5. Specific heat versus temperature

\section{Thermal Analysis of the Problem}

Transient heat conduction in 3D heat-transfer problem is governed by the following differential equation [40]:

$$
-\left(\frac{\partial q_{x}}{\partial x}+\frac{\partial q_{y}}{\partial y}+\frac{\partial q_{z}}{\partial z}\right)+Q=\rho C_{p} \frac{\partial T}{\partial t}
$$

where $q_{x}, q_{y}$ and $q_{z}$ are the conduction heat fluxes in $x$, $y$, and $z$ directions, respectively; $C_{p}$ is the specific heat; $\rho$ is the specific mass; $Q$ is the internal heat generation rate per unit volume; and $T$ is the temperature that varies with the coordinates as well as the time $t$. The conduction heat fluxes can be written in terms of temperature using Fourier's law. Assuming constant and uniform thermal properties, the relations are

$$
q_{x}=-k_{x} \frac{\partial T}{\partial x}, q_{y}=-k_{y} \frac{\partial T}{\partial y}, q_{z}=-k_{z} \frac{\partial T}{\partial z}
$$

where $k_{x}, k_{y}$,and $k_{z}$ are the thermal conductivities in $x$, $y$ and $z$ directions, respectively. Heat transfer boundary conditions consist of several heat transfer modes that can be written in different forms. The boundary conditions frequently encountered are as follows $[41,42]$ :

$$
T_{s}=T_{1}(x, y, z, t)
$$

$$
-q_{s}=h\left(T_{s}-T_{\infty}\right)
$$

Where $T_{1}$ is the specified surface temperature; $q_{s}$ the specified surface heat flux (positive into a surface); $h$ is the convective heat transfer coefficient; $T_{S}$ the unknown surface temperature; and $T_{\infty}$ the convective exchange temperature.

\section{Modeling in ANSYS CFX}

The finite volume method consists of three stages: the formal integration of the governing equations of the fluid flow over the entire (finite) control volumes of the solution domain. Then, discretization, involving the substitution of a variety of finite-difference-type approximations for the terms in the integrated equation representing flow processes such as convection, diffusion, and sources. This converts the integral equation into a system of algebraic equations, which can then be solved using iterative methods [43]. The first stage of the process, the control volume integration, is the step that distinguishes the finite volume method from other CFD methods. The statements resulting from this step express the "exact" conservation of the relevant properties for each finite cell volume. This gives a clear relationship between the numerical analog and the principle governing the flow. To enable the modeling of a rotating body (in this case the disk) the code employs the rotating reference frame technique. For the preparation of the mesh of CFD model, one defines initially, various surfaces of the disk in ICEM CFD as shown in the Figure 6; we used a linear tetrahedral element with 30717 nodes and 179798 elements. In order not to weigh down calculation, an irregular mesh is used in which the mesh is broader where the gradients are weaker (nonuniform mesh), (Figure 7).

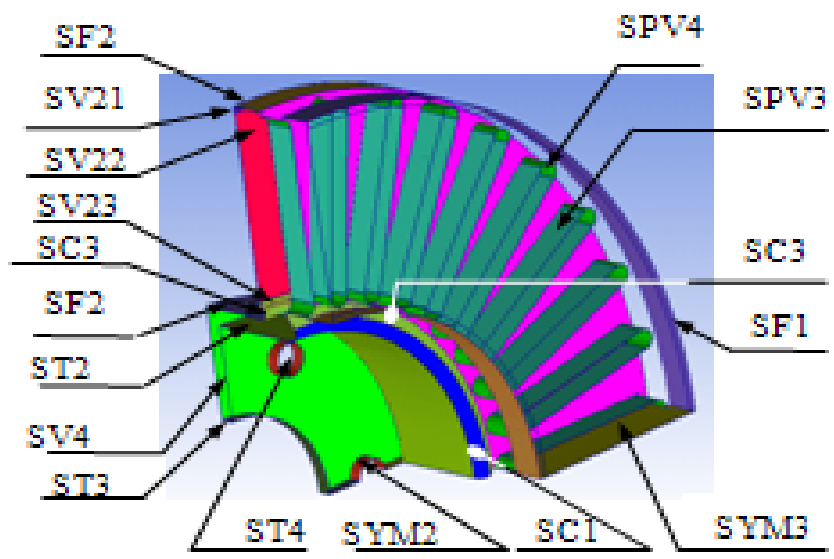

Figure 6. Definition of surfaces of the ventilated disk

The CFD models were constructed and were solved using ANSYS-CFX software package [44]. The model applies periodic boundary conditions on the section sides. As the brake disk is made from sand-casted grey cast iron, the disk model is attached to an adiabatic shaft, the axial length of which spans that of the domain. Air around the disk is considered to be $20^{\circ} \mathrm{C}$, and open boundaries with zero relative pressure were used for the upper lower, and radial ends of the domain. Material data were taken from 
ANSYS material data library for air at $20^{\circ} \mathrm{C}$. Reference pressure was set to be $1 \mathrm{~atm}$, low turbulence intensity and the turbulent model used was k- $\varepsilon$. (Figure 8).

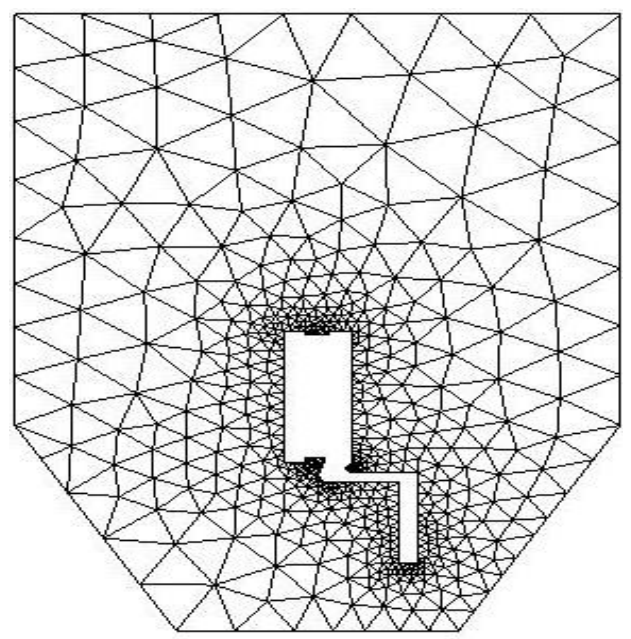

Figure 7. Irregular mesh in the wall

Symmetric wall air

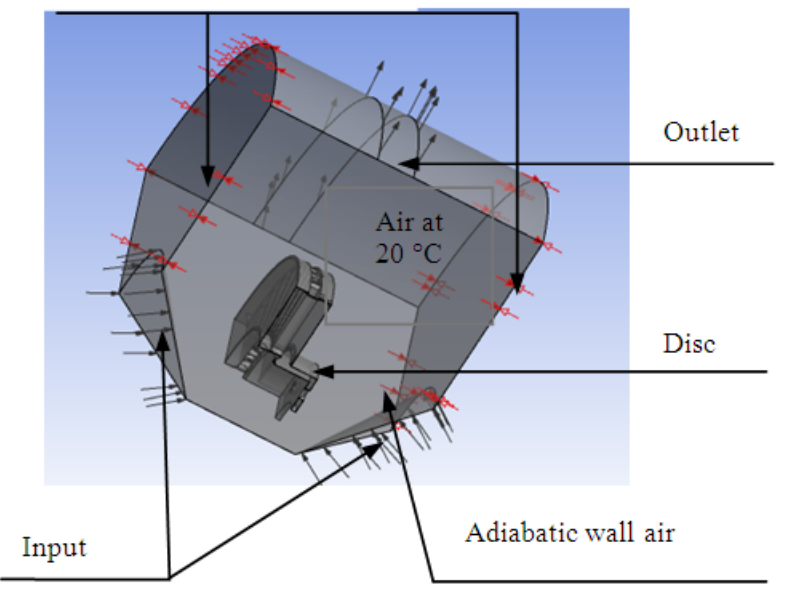

Figure 8. Brake disk CFD model

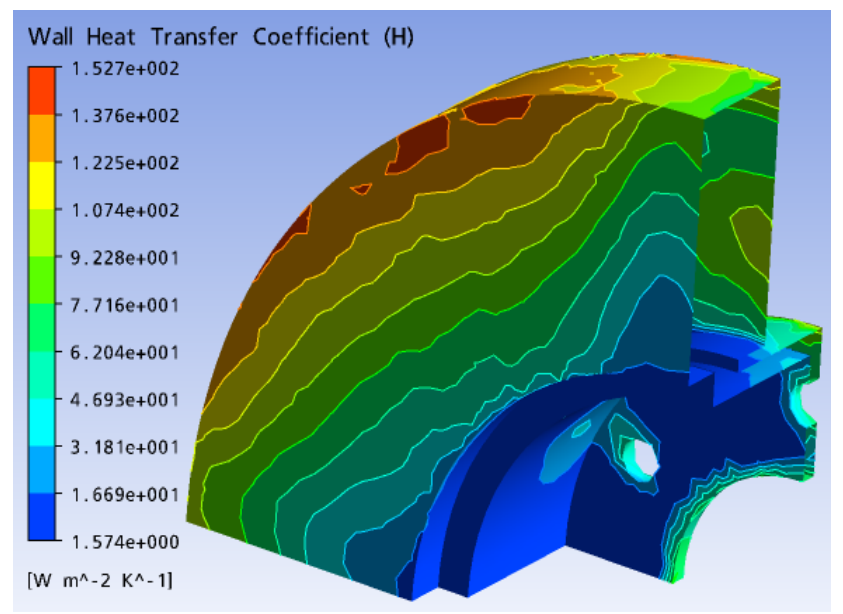

Figure 9. Distribution of heat transfer coefficient on a full disk in the steady state case (FG 15)

The airflow through and around the brake disk was analyzed using the ANSYS CFX software package. The ANSYS-CFX solver automatically calculates heat transfer coefficient at the wall boundary. Afterwards the heat transfer coefficients considering convection were calculated and organized in such a way, that they could be used as a boundary condition in thermal analysis. Averaged heat transfer coefficient had to be calculate for all disk using ANSYS CFX Post as it is indicated in Figure 9 and Figure 10.

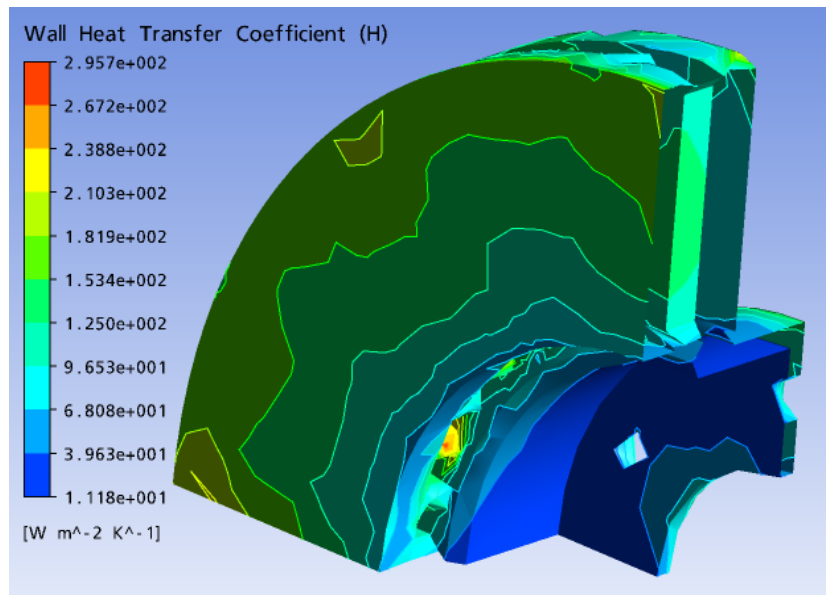

Figure 10. Distribution of heat transfer coefficient on a ventilated disk in the steady state case (FG 15)

\section{a) Results of the calculation of the heat transfer coefficient $h$}

The heat transfer coefficient is a parameter relates with the velocity of air and the shape of brake disk, and many other factors. In different velocity of air, the heat transfer coefficient in different parts of brake disk changes with time [45]. Heat transfer coefficient will depend on air flow in the region of brake rotor and vehicle speed, but it does not depend on material.

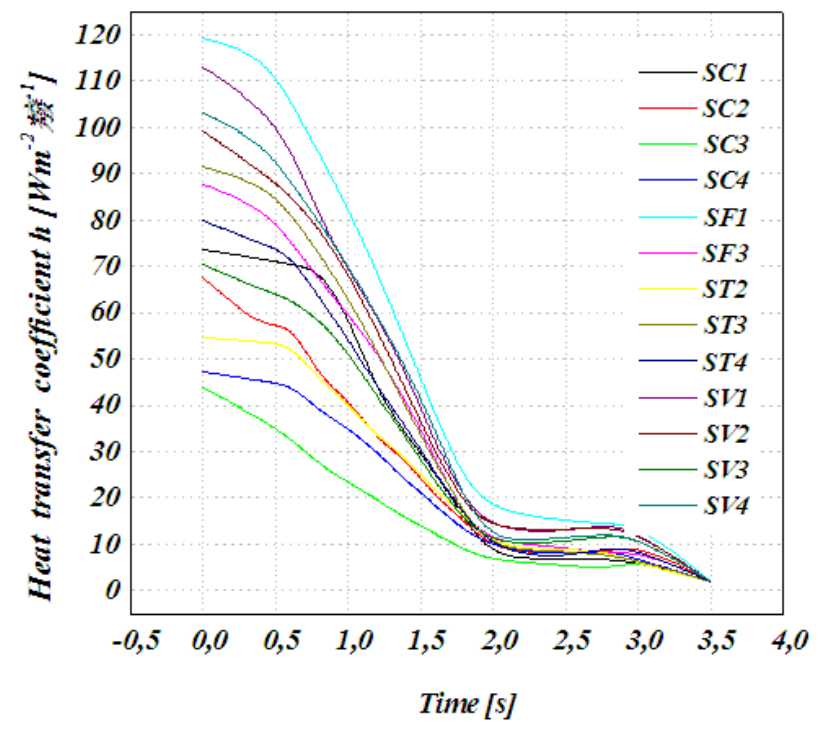

Figure 11. Variation of heat transfer coefficient (h) of various surfaces for a full disk in transient case (FG 15)

From the comparison between Figure 11 and Figure 12 concerning the variation of heat transfer coefficient in the nonstationary mode for the two types of design, full and ventilated, one notes that the introduction of the system of ventilation directly influences the value of this coefficient for same surface, which is logically significant because this mode of ventilation results in the reduction in the differences of wall-fluid temperatures. 


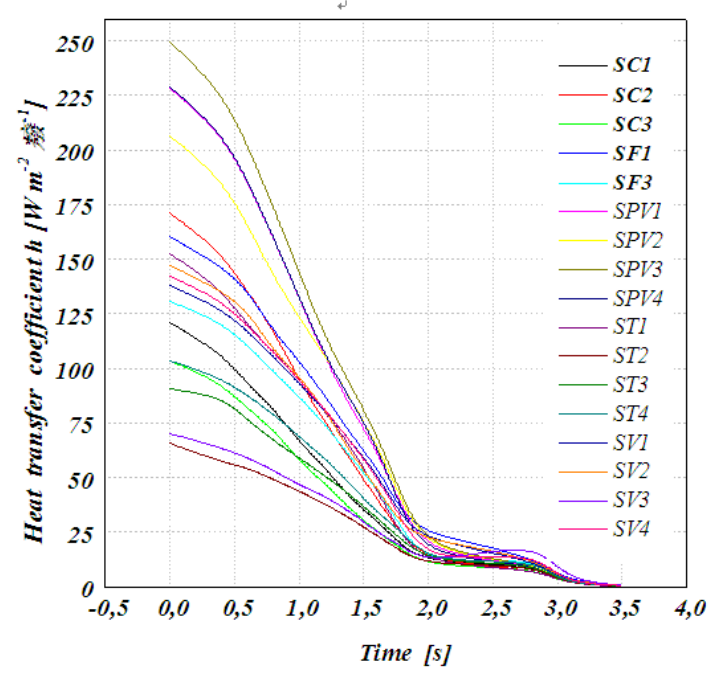

Figure 12. Variation of heat transfer coefficient (h) of various surfaces for a ventilated disk in transient case (FG 15)

\section{Determination of the Disk Temperature}

The modeling of the disk temperature is carried out by simulating a stop braking of a middle class car (braking of type 0).

The characteristics of the vehicle and of the disk brake are listed in Table 1.

The vehicle speed decreases linearly with time until the value 0 as shown in Figure 13. The variation of the heat flux during the simulation time is represented on the Figure 14.

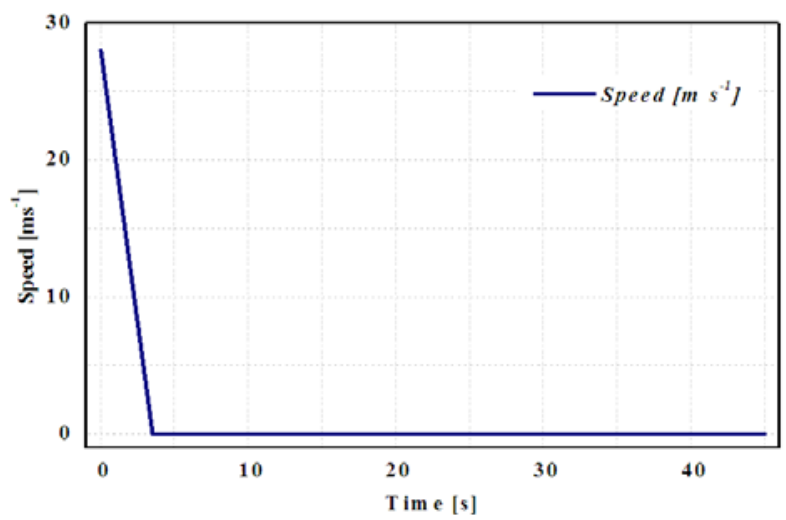

Figure 13. Speed of braking versus time (braking of type 0)

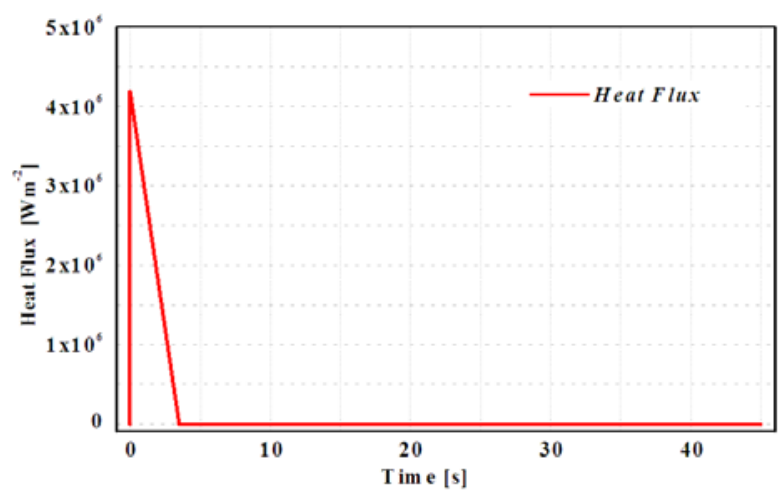

Figure 14. Heat Flux versus time

\section{Meshing of the Disk}

The elements used for the mesh of the full and ventilated disk are tetrahedral 3D elements with 10 nodes (isoparamitric) (Figure 15).

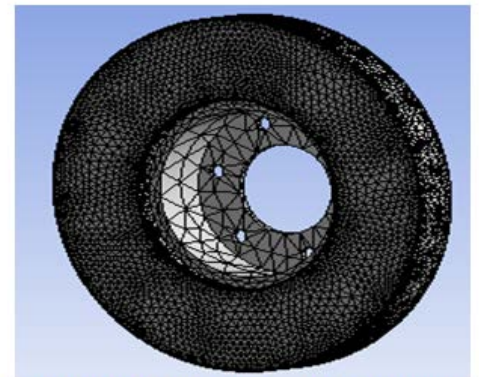

(a) full disk (172103 nodes -114421 elements)

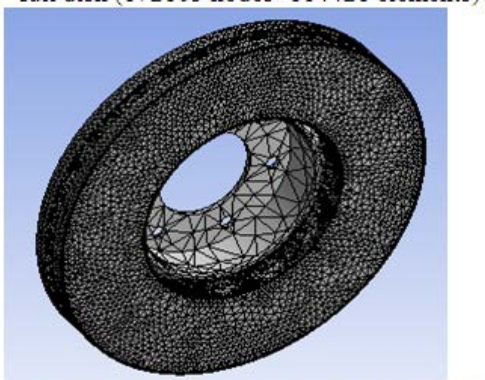

(b) ventilated disk (154679 nodes- 94117 elements)

Figure 15. Meshing of the disk (a) full disk (172103 nodes -114421 elements (b) ventilated disk (154679 nodes- 94117 elements)

\section{Initial and Boundary Conditions}

The boundary conditions are introduced into module ANSYS Workbench [Multiphysics], by choosing the mode of first simulation of the all (permanent or transitory), and by defining the physical properties of materials. These conditions constitute the initial conditions of our simulation. After having fixed these parameters, one introduces a boundary condition associated with each surface.

- Total time of simulation $=45 \mathrm{~s}$

- Increment of initial time $=0.25 \mathrm{~s}$

- Increment of minimal initial time $=0.125 \mathrm{~s}$

- Increment of maximal initial time $=0.5 \mathrm{~s}$

- Initial temperature of the disk $=20^{\circ} \mathrm{C}$

- Materials: Grey Cast iron FG 15.

- Convection: One introduces the values of the heat transfer coefficient $(h)$ obtained for each surface in the shape of a curve (Figure 11, Figure 12)

- Flux: One introduces the values obtained by flux entering by means of the code CFX.

\section{Results and Discussions}

\subsection{Influence of Construction of the Disk}

Figure 16 and Figure 17 show the variation in the temperature according to time during the simulation. From the first step, the variation in the temperature shows a great growth which is due to the speed of the physical course of the phenomenon during braking, namely friction, plastic microdistortion of contact surfaces. 

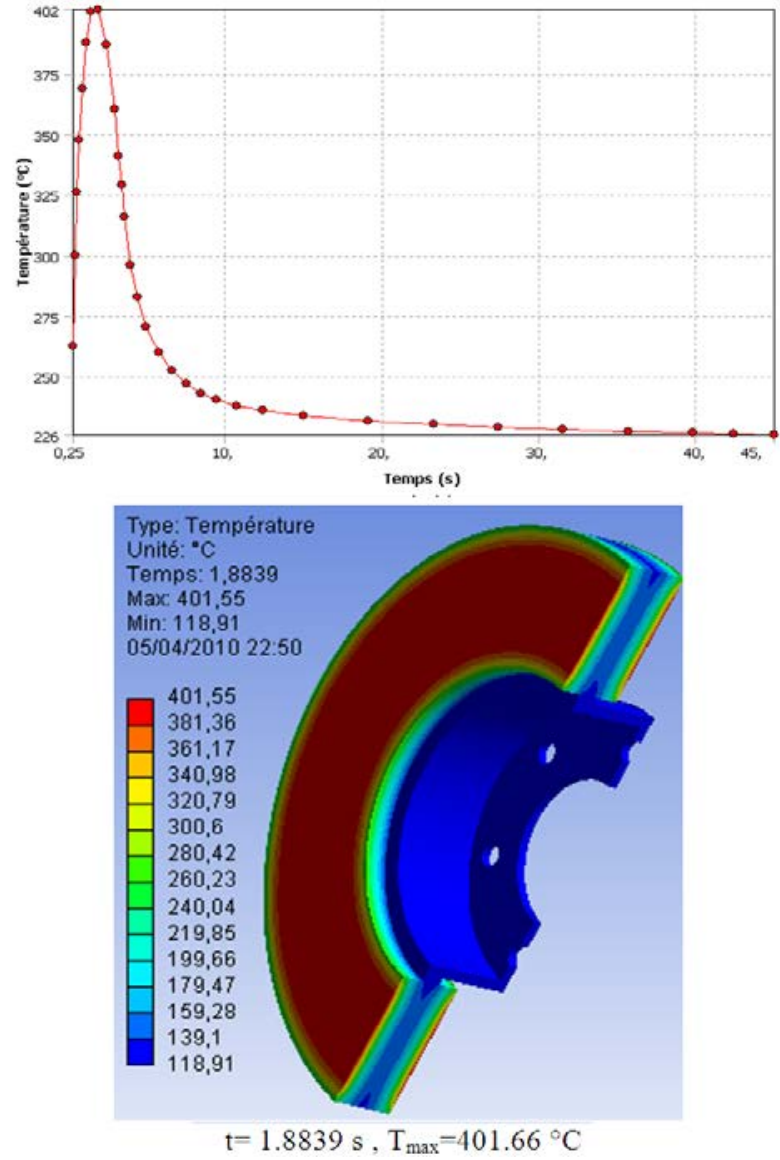

Figure 16. Temperature distribution of a full disk of cast iron (FG 15)
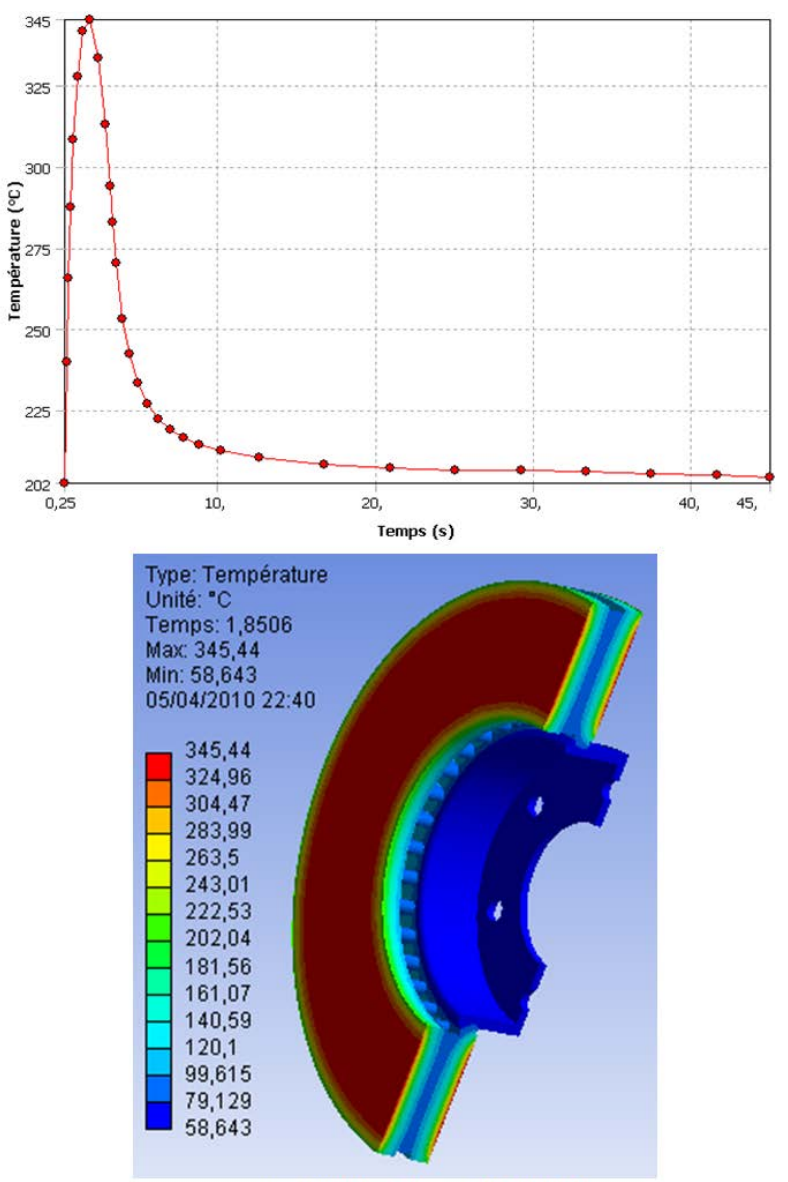

$\mathrm{t}=1.8506 \mathrm{~s}, \mathrm{~T}_{\max }=346.44^{\circ} \mathrm{C}$

Figure 17. Temperature distribution of a ventilated disk of cast iron (FG 15)
For the full disk, the temperature reaches its maximum value of $401.55{ }^{\circ} \mathrm{C}$ at the moment $t=1.8839 \mathrm{~s}$, and then it falls rapidly up to $4.9293 \mathrm{~s}$, as from this moment and up to the end $(t=45 \mathrm{~s})$ of simulation, the variation in the temperature become slow. It is noted that the interval [03.5] s represents the phase of forced convection. During this phase, one observes the case of the free convection until the end of the simulation. In the case of the ventilated disk, one observes that the temperature of the disk falls approximately by $60{ }^{\circ} \mathrm{C}$ compared with the first case. It is noted that ventilation in the design of the disks of brake plays an important role in producing a better system of cooling.

Figure 18 and Figure 19 respectively show the temperature variation according to the thickness and radius. It is noted that there is an appreciable variation of temperature between the two types of full and ventilated disk. The influence of ventilation on the temperature field appears clearly at the end of the braking $(t=3.5 \mathrm{~s})$.
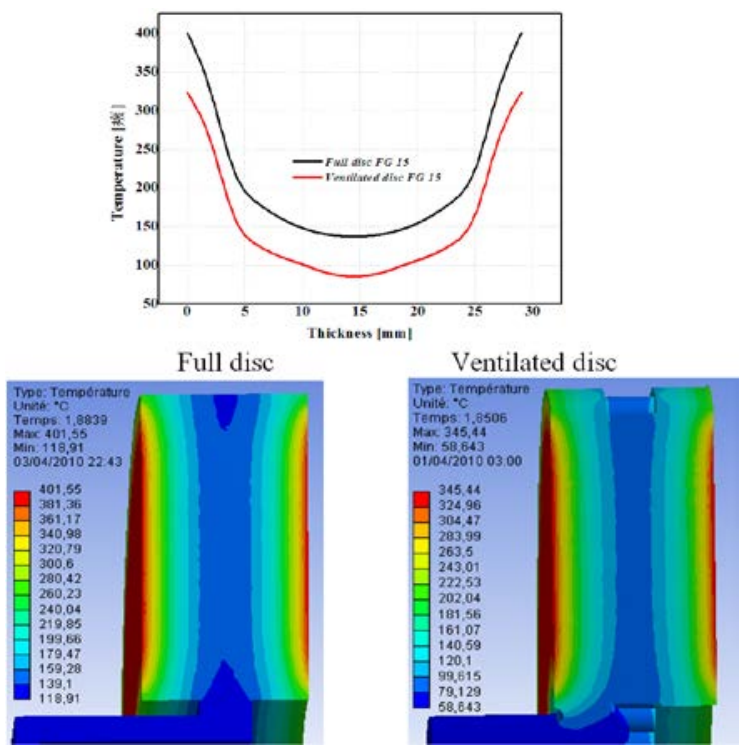

Figure 18. Temperature variation through the thickness for both designs with same material (FG15)

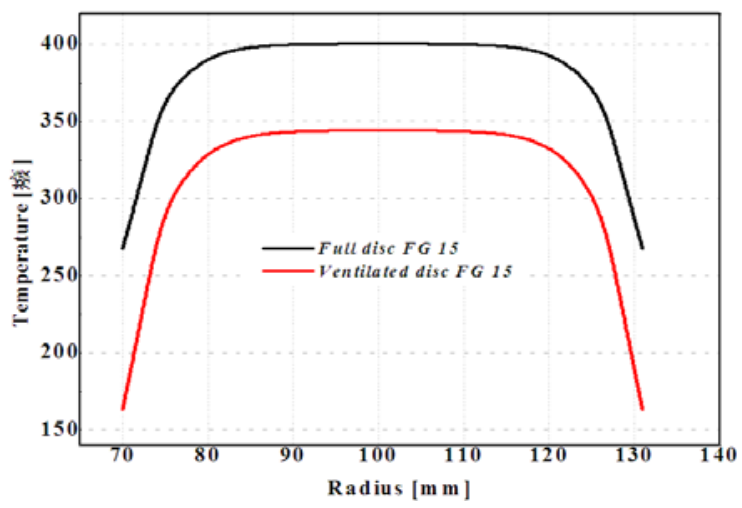

Figure 19. Temperature variation through a radius or both designs with the same material (FG15)

\section{Coupled Thermo-Mechanical Analysis}

\subsection{FE model and boundary conditions}

A commercial front disk brake system consists of a rotor that rotates about the axis of a wheel, a caliper- 
piston assembly where the piston slides inside the caliper, which is mounted to the vehicle suspension system, and a pair of brake pads. When hydraulic pressure is applied, the piston is pushed forward to press the inner pad against the disk and simultaneously the outer pad is pressed by the caliper against the disk [46]. Figure 20 shows the FE model and boundary conditions embedded configurations of the model composed of a disk and two pads. The initial air temperature of the disk and pads is $20^{\circ} \mathrm{C}$, and the surface convection condition is applied at all surfaces of the disk and the heat transfer coefficient (h) of $5 \mathrm{~W} / \mathrm{m}^{2}{ }^{\circ} \mathrm{C}$ is applied to the surfaces of the two pads. The FE mesh is generated using 3D tetrahedral element with 10 nodes (solid 187) for the disk and pads. Overall, 185901 nodes and 113367 elements are used (Figure 21).

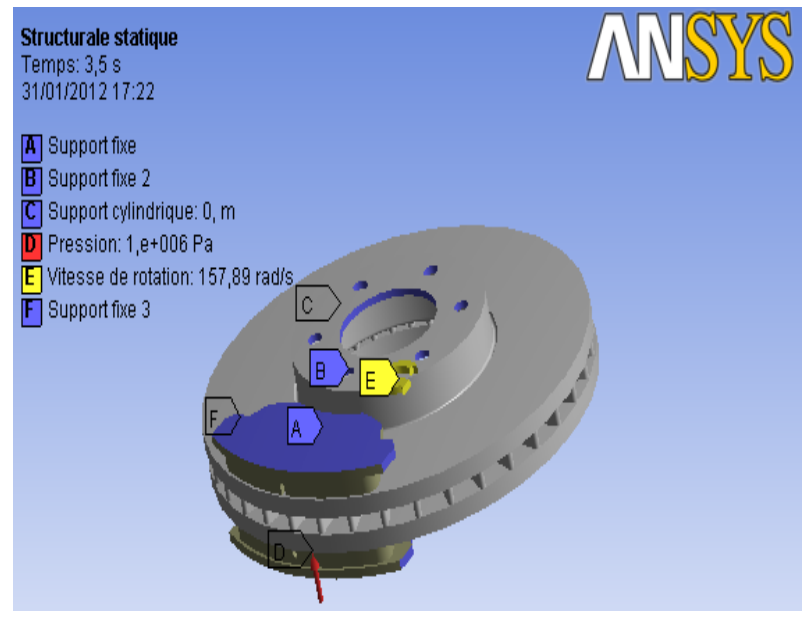

Figure 20. Boundary conditions and loading imposed on the disk-pads

In this study, a transient thermal analysis will be carried out to investigate the temperature variation across the disk
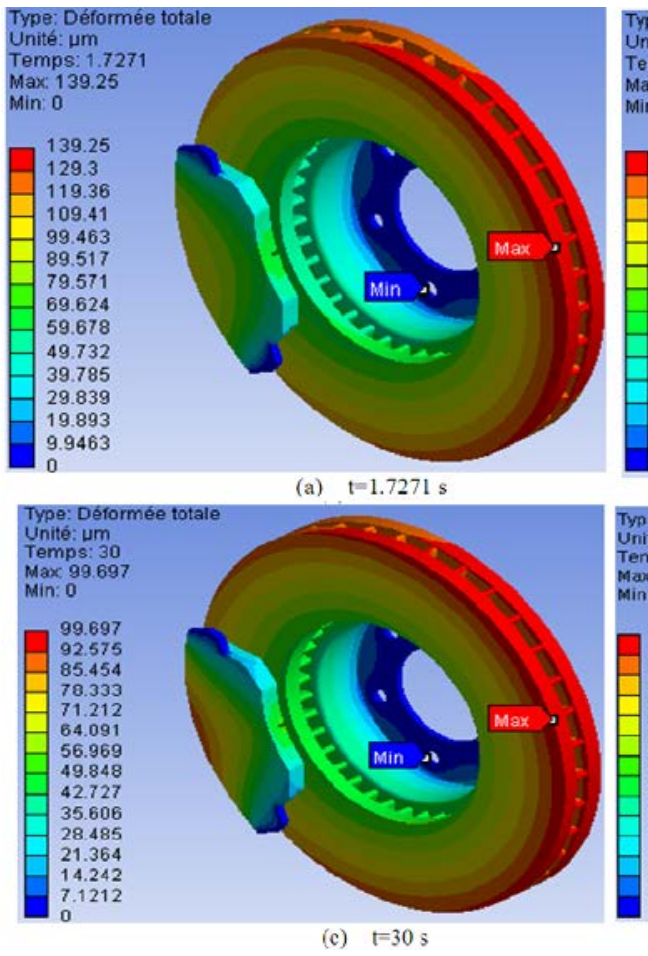

Figure 22. Total distortion distribution

Figure 22 gives the distribution of the total distortion in the whole (disk-pads) for various moments of simulation. For this figure, the scale of values of the deformation

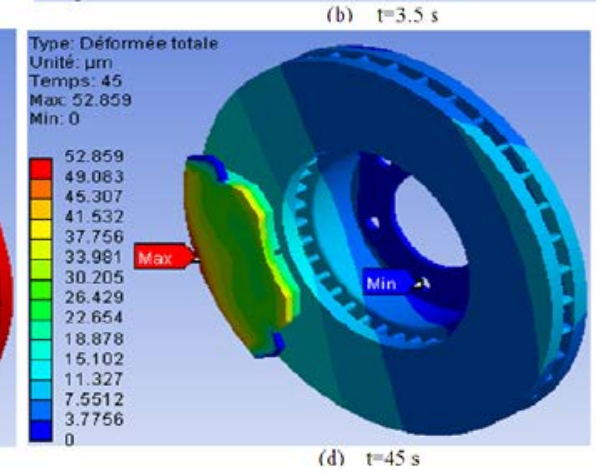

using ANSYS software. Further structural analysis will also be carried out by coupling thermal analysis.

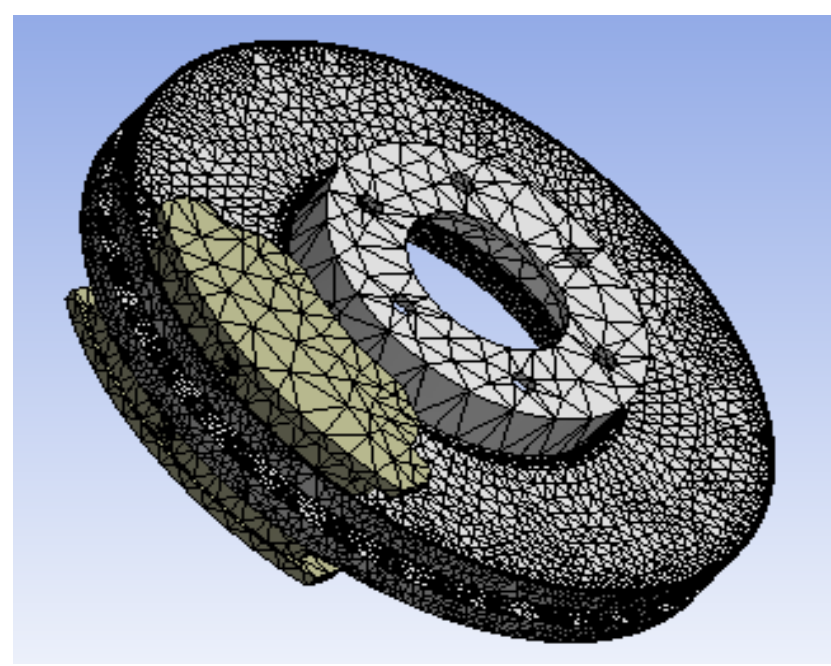

Figure 21. Refined mesh of the model

\subsection{Thermal Deformation}

Due to thermal deformation, contact area and pressure distribution also change. Thermal and mechanical deformations affect each other strongly and simultaneously. The deformation of the disk material gradually increases in the radial direction of the disk, and becomes the highest at the circumference region. The deformation of the brake disk due to thermal loading is apparent when viewed through the disk cross section. The thermal deformation of the rotor due to frictional heating produces a non-uniform pressure distribution between the disk and pad. The deformation of the brake disk region is primarily attributed to the thermal expansion of the disk.

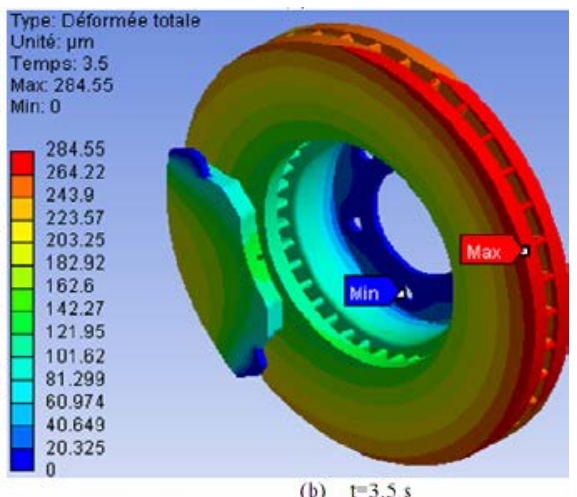

varies from 0 to $284.55 \mu \mathrm{m}$. The value of the maximum displacement recorded during this simulation is at the moment, $\mathrm{t}=3.5 \mathrm{~s}$, which corresponds to the time of braking. 
One observes a strong distribution which increases with time on the friction tracks, and the external crown and the cooling fins of the disk. Indeed, during a braking moment, the maximum temperature depends almost entirely on the
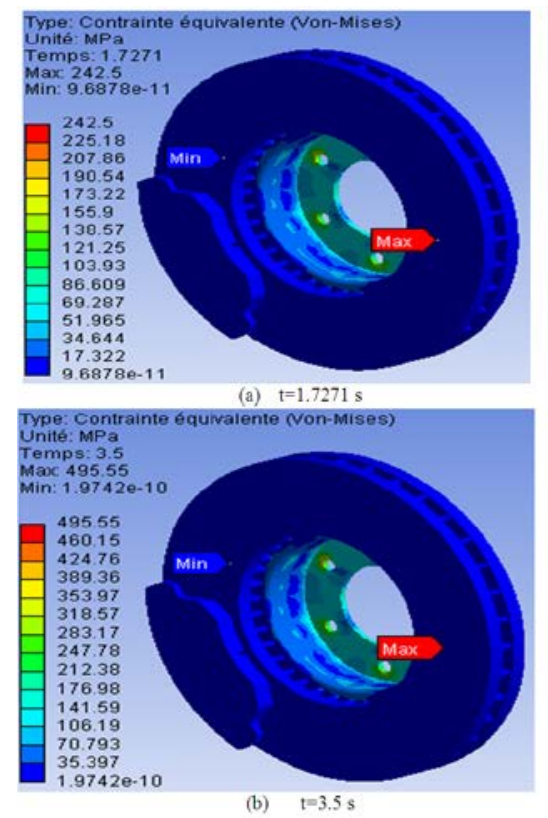

heat storage capacity of disk (on particular tracks of friction); this deformation will generate an asymmetry of the disk following the rise of temperature which will cause a deformation in the shape of an umbrella.
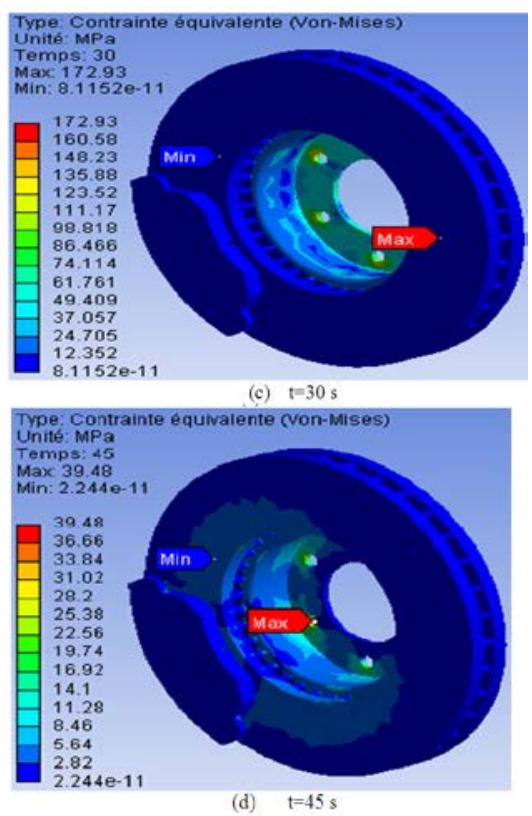

Figure 23. Von Mises stress distribution

\subsection{Von Mises Stress Distribution}

Figure 23 presents the distribution of the constraint equivalent of Von Mises for various moments of simulation, the scale of values varying from 0 to 495.56 MPa. The maximum value recorded during this simulation of the thermomechanical coupling is very significant compared to that obtained with the assistance in the mechanical analysis under the same conditions. One observes a strong constraint on the level of the bowl of the disk. Indeed, the disk is fixed to the hub of the wheel by screws, thus preventing its movement. In the present of the rotation of the disk and the requests of torsional stress and shears generated at the level of the bowl which are able to create the stress concentrations. The repetition of these effects will lead to risks of rupture on the level of the bowl of the disk.

\subsection{Contact Pressure}

Figure 24. shows the contact pressure distribution in the friction interface of the inner pad taken at various times of simulation.For this distribution, the scale varies from 0 to 3.3477 $\mathrm{MPa}$ and reached a value of pressure at the moment $t=3.5 \mathrm{~s}$, which corresponds to the null rotational speed. It is also noticed that the maximum contact pressure is located on the edges of the pad decreasing from the leading edge toward the trailing edge from friction. This pressure distribution is almost symmetrical compared with the groove, and it has the same tendency as that of the distribution of the temperature because the highest area of the pressure is located in the same sectors. Indeed, at the time of the thermomechanical coupling of $3 \mathrm{D}$, the pressure produces the symmetric field of the temperature. This last one affects thermal dilation and leads to a variation of the contact pressure distribution.
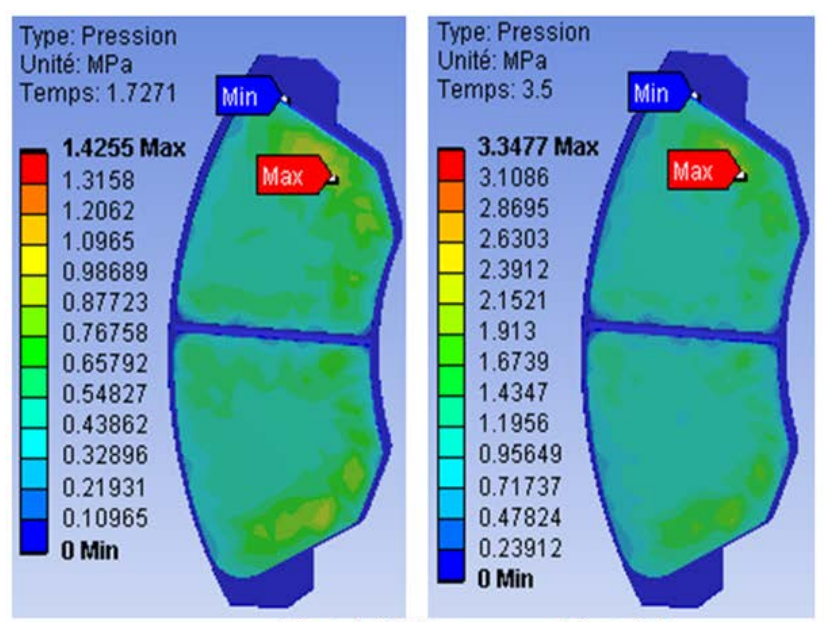

(a) $\mathrm{t}=1.7271 \mathrm{~s}$

(b) $t=3.5 \mathrm{~s}$

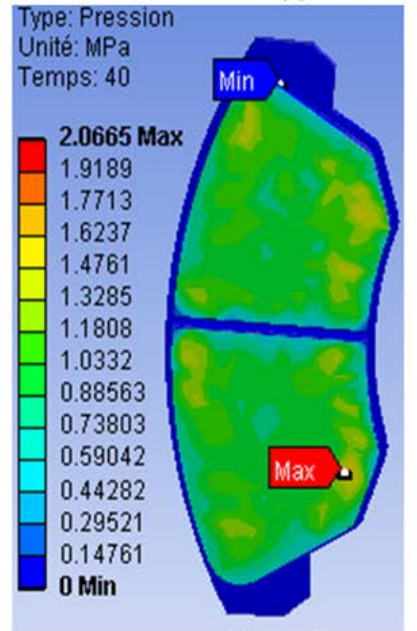

(c) $\mathrm{t}=40 \mathrm{~s}$

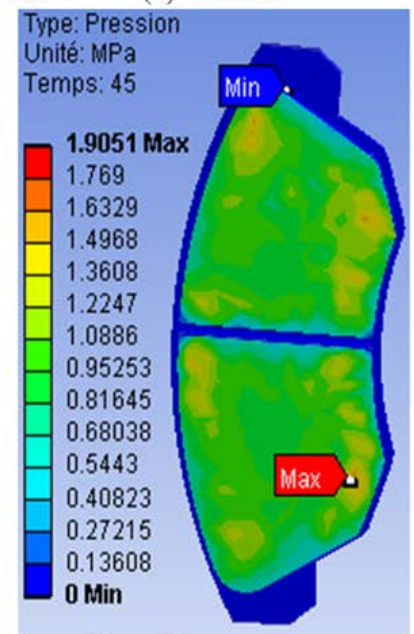

(d) $t=45 \mathrm{~s}$
Figure 24. Contact pressure distribution in the inner pad 


\section{Conclusion}

In this article, we have presented the analysis of thermomechanical behavior of the dry contact between the brake disk and pads during the braking process; the modeling is based on the ANSYS 11.0. We have shown that the ventilation system plays an important role in cooling the disks and provides a good high temperature resistance. The analysis results showed that, temperature field and stress field in the process of braking phase were fully coupled. The temperature, Von Mises stress, and the total deformations of the disk and contact pressures of the pads increases as the thermal stresses are apart from the mechanical stress which causes the crack propagation and fracture of the bowl and wear of the disk and pads. Regarding the calculation results, it would be interesting to solve the problem in thermomechanical disk brakes with an experimental study to validate the numerical results, for example, on test benches, in order to demonstrate a good agreement between the model and reality.

Regarding the outlook, there are three recommendations for the expansion of future work related to disk brake that can be done to further understand the effects of thermomechanical contact between the disk and pads, the recommendations are as follows:

- Experimental study to verify the accuracy of the numerical model developed.

- Tribological and vibratory study of the contact disk pads;

- Study of dry contact sliding under the macroscopic aspect (macroscopic state of the surfaces of the disk and pads).

\section{References}

[1] Milenković, P. D. et al. (2010) The influence of brake pads thermal conductivity on passanger car brake system efficiency. Therm. Sci. Vol. 14(Suppl.), S221-S230.

[2] K. J. Lee and J. R. Barber, "An Experimental Investigation of Frictionally-Excited Thermoelastic Instability in Automotive Disk Brakes Under a Drag Brake Application”, J.Tribol, vol. 116, 1994, pp. 409-414.

[3] O. Altuzarra, E. Amezua, R. Aviles and A. Hernandez, "Judder vibration in disc brakes excited by thermoelastic instability”, Eng. comput, vol. 19, no. 4, 2002, pp. 411-430.

[4] Y. H. Jang and S. H. Ahn, "Frictionally-excited thermoelastic instability in functionally graded material”, Wear, vol. 262, 2007, pp. 1102-1112.

[5] B. Y. Yi, J. R. Barber and P. Zagrodzki, "Eigenvalue solution of thermoelastic instability problems using Fourier reduction”, Proc. R. Soc. London, A, vol. 456, 2000, pp. 2799-282.

[6] Nakatsuji, T,. Okubo, K,.., Fujii.T, Sasada, M,. Noguchi, Y,.(2002) Study on Crack Initiation at Small Holes of One - piece Brake Discs. SAE Technical Paper, Inc, Humble, 2 002-01-0926.

[7] Valvano, T., Lee, K: (2000) An Analytical Method to Predict Thermal Distortion of a Brake Rotor. SAE Technical Paper, Inc, Humble, 2000-01-0445.

[8] Hudson, M.D, Ruhl, R.L (1997) Ventilated Brake Rotor Air Flow Investigation. SAE Technical Paper, Inc,Humble, 01-033.

[9] Denape.J, Laraqi. N : (2000) Aspect thermique du frottement: mise en évidence expérimentale et éléments de modélisation, Mec. Ind, 1, 563-579.

[10] Hamraoui, M., (2009)Thermal behaviour of rollers during the rolling process, Appl. Therm. Eng, 29 (11-12) 2386-2390.

[11] Hamraoui, M., Zouaoui, Z., (2009) Modelling of heat transfer between two rollers in dry friction, Int. J. Therm. Sci. 48 (6) 12431246.
[12] N. Laraqi, (1997) Velocity and relative contact size effect on the thermal constriction resistance in sliding solids, ASME J. Heat Transf., 119, 173-177.

[13] H. Yapıcı, M. S. Genç, G. Özısık, (2008) Transient temperature and thermal stress distributions in a hollow disk subjected to a moving uniform heat source, J.Therm.Stress 31 476-493.

[14] N. Laraqi, N. Alilat, J.M. Garcia-de-Maria, A. Baïri, (2009) Temperature and division of heat in a pin - on-disc frictional device - exact analytical solution, Wear, 266 (7-8) 765-770.

[15] J.G. Bauzin, N. Laraqi, (2004) Simultaneous estimation of frictional heat flux and two thermal contact parameters for sliding solids, Numer. Heat Transf. 45 (4) 313-328.

[16] A. Baïri, J.M. Garcia-de-Maria, N. Laraqi, (2004) Effect of thickness and thermal properties of film on the thermal behavior of moving rough interfaces,Eur. Phys. J. Appl. Phys. 26 (1) 29-34.

[17] Mijuca, D. M., iberna A. M., Medjo B. I (2005) A new multifield finite element method in steady state heat analysis. Therm. Sci.. 9(1), 111-130.

[18] Gao CH, Lin XZ (2002) Transient temperature field analysis of a brake in a non-axisymmetric three-dimensional model. J Mat Proc Tech 129: 513-517.

[19] Talatia Faramarz and Jalalifar S, (2000) Analysis of heat conduction in a disk brake system. J Heat Mass Transfer 45 : 1047-1059.

[20] Naji M, Al-Nimr M, Masoud S (2000) Transient 5thermal behavior of a cylindrical brake system. J Heat Mass Transf 36:4549.

[21] Mosleh M, Blau PJ, Dumitrescu D (2004) Characteristics and morphology of wear particles from laboratory testing of disk brake materials. J Wear 256: 1128-1134.

[22] Mutlu I, Alma MH, Basturk MA (2005) Preparation and characterization of brake linings from modified tannin-phenol formaldehyde resin and asbestos-free fillers. J Mat Sci 40 (11): 3003-3005.

[23] Hecht RL, Dinwiddie RB, Wang H (1999) The effect of graphite flake morphology on the thermal diffusivity of gray cast irons used for automotive brake discs. J Mat Sci 34 (19): 4775-4781.

[24] Gudmand-Høyer L, Bach A, Nielsen GT, Morgen P (1999) Tribological properties of automotive disc brakes with solid lubricants. J Wear 232 (2): 168-175.

[25] Uyyuru RK, Surappa MK, Brusethaug S (2007) Tribological behavior of Al-Si-SiCp composites/automobile brake pad system under dry sliding conditions. J Tribol Int 40 (2): 365-373.

[26] Cho MH, Cho KH, Kim SJ, Kim DH, Jang H (2005) The role of transfer layers on friction characteristics in the sliding interface between friction materials against gray iron brake disks. Trib Lett 20 (2): 101-108.

[27] Boz M, Kurt A (2007) The effect of Al2O3 on the friction performance of automotive brake friction materials. J Tribo Int 40 (7): 1161-1169.

[28] Blau PJ, McLaughlin JC (2003) Effects of water films and sliding speed on the frictional behavior of truck disc brake material. Trib Int 36 (10): 709-715.

[29] McPhee AD, Johnson DA (2007) Experimental heat transfer and flow analysis of a vented brake rotor. Int J Thermal Sci 47 (4): 458-467.

[30] Wallis L, Leonardi E, Milton B, Joseph P (2002) Air flow and heat transfer in ventilated disk brake rotors with diamond and tear-drop pillars. Numer Heat Transf Part A 41: 643-655.

[31] Johnson DA, Sperandei BA, Gilbert R (2003) Analysis of the flow through a vented automotive brake rotor. J Fluids Eng 125:979986.

[32] Kang.S.S, Cho.S.K (2012) Thermal deformation and stress analysis of disk brakes by finite element method Journal of Mechanical Science and Technology 26 (7) (2012) 2133-2137.

[33] Thilak.VMM, R.Krishnaraj, (2011), Transient thermal and structural analysis of the rotor disc of disc brake, International Journal of Scientific \& Engineering Research Volume 2, Issue 8, August-2011.

[34] Zhang, L., Yang, Q., Weichert,D., Nanlin T., (2009) Simulation and analysis of thermal fatigue based on imperfection model of brake discs, Beijing Jiaotong University, PAMM Proc. Appl. Math. Mech. 9, 533-534.

[35] Fiche U.I.C. 541-3 (1993)FREIN - Frein à disques et garnitures de frein à disques, 4eédition, 1 Jury.

[36] Saumweber, E., (1969) Temperaturberechnung in Bremsscheiben fürein beliebiges Fahrprogramm,Leichtbau der Verkehrsfahrzeuge, Heft 3, Augsburg. 
[37] Cruceanu, C.: (2007) Frâne pentru vehicule feroviare (Brakes for railway vehicles). MATRIXROM (ed.), Bucureşti, 978-973-755200-6.

[38] Reimpel J. (1998) Technologie de freinage. Vogel Verlag, Würzburg.

[39] Gotowicki,P.F.,; Nigrelli,V.,; Mariotti,G.V., (2005). Numerical and experimental analysis of a pegs-wing ventilated disk brake rotor, with pads and cylinders, Jnc: 10 th EAEC European Automotive Congress -Paper EAEC05YUAS04-P 5, June.

[40] Yu, H., et al.: (2011) Study on temperature distribution due to freezing and thawing at the Fengman concrete gravity dam, Therm. Sci, 15, (suppl. 1), s27-s32.

[41] Sergerlind, L.J.,(1984)Applied Finite Element Analysis. Wiley, New York.
[42] Hinton, E., Owen, D. R. J., (1981) An Introduction toFinite Element Computations, Pineridge Press, Swansea.

[43] Versteeg, H.K., Malalasekera, W (1995) An Introduction to Computational Fluid Mechanics, The Finite Volume Method Pearson, Prentice Hal.

[44] ANSYS v.11 User'Manual guide.

[45] Zhang, J.,Xia,C. (2012).Research of the Transient Temperature Field and Friction Properties on Disc Brakes, Proceedings of the 2012 2nd International Conference on Computer and Information Application (ICCIA 2012) 201-204.

[46] Nouby, M., Srinivasan, K. (2009).Parametric studies of disk brake squeal using finite element Approach. J. Mek. No. 29, 52-66. 